\title{
Papers
}

\section{Smoking and risk of myocardial infarction in women and men: longitudinal population study}

\author{
Eva Prescott, Merete Hippe, Peter Schnohr, Hans Ole Hein, Jørgen Vestbo
}

\begin{abstract}
Objective: To compare risk of myocardial infarction associated with smoking in men and women, taking into consideration differences in smoking behaviour and a number of potential confounding variables. Design: Prospective cohort study with follow up of myocardial infarction.

Setting: Pooled data from three population studies conducted in Copenhagen.

Subjects: 11472 women and 13191 men followed for a mean of 12.3 years.

Main outcome measures: First admission to hospital or death caused by myocardial infarction.

Results: 1251 men and 512 women had a myocardial infarction during follow up. Compared with non-smokers, female current smokers had a relative risk of myocardial infarction of 2.24 (range 1.85-2.71) and male smokers 1.43 (1.26-1.62); ratio 1.57

(1.25-1.97). Relative risk of myocardial infarction increased with tobacco consumption in both men and women and was higher in inhalers than in non-inhalers. The risks associated with smoking, measured by both current and accumulated tobacco exposure, were consistently higher in women than in men and did not depend on age. This sex difference was not affected by adjustment for arterial blood pressure, total and high density lipoprotein cholesterol concentrations, triglyceride concentrations, diabetes, body mass index, height, alcohol intake, physical activity, and level of education. Conclusion: Women may be more sensitive than men to some of the harmful effects of smoking. Interactions between components of smoke and hormonal factors that may be involved in development of ischaemic heart disease should be examined further.
\end{abstract}

\section{Introduction}

Ischaemic heart disease is responsible for about $40 \%$ of deaths in Western countries, with smoking as a major modifiable risk factor. ${ }^{1}$ The steep rise in the worldwide prevalence of smoking among women is expected to continue in the near future. At the start of the smoking epidemic, female smokers were few and differed extensively from male smokers in factors such as age of starting smoking, amount smoked, and inhalation habits, and the risk associated with smoking in women may have been underestimated. ${ }^{2-4}$ Within the past two or three decades male and female smoking habits have become similar, and a more fair comparison of the risk associated with smoking in both sexes based on recent prospective population studies is now possible. From a public health point of view, as well as a clinical point of view, it is important to recognise sex differences in risk associated with smoking and elucidate possible mechanisms by which these differences could act.

We recently found that the relative mortality from vascular disease was higher in female smokers than in male smokers. ${ }^{5}$ Consequently, we aimed to examine sex differences in smoking related risk of myocardial infarction while simultaneously including multiple cardiovascular risk factors in a prospective population study conducted in Copenhagen.

\section{Methods}

This study is based on data from three longitudinal population studies: the Copenhagen city heart study, with 15789 subjects from central Copenhagen; the Glostrup population studies, with 6341 subjects from Copenhagen suburbs; and the Copenhagen male study, which sampled 3355 subjects from 14 large workplaces. All datasets with sufficient information on cardiovascular risk factors were included. The study population is outlined in table 1 . Overall response rate at first examination was 77\% (range 69-88\%).

Cardiovascular risk factors were assessed by a self administered questionnaire and various laboratory tests. Tobacco consumption was studied in six categories: never smokers; ex-smokers; non-inhaling current smokers; and inhaling current smokers of $1-14,15-24$, and $\geqslant 25 \mathrm{~g}$ tobacco per day. Type of tobacco (cigarette, cheroot, cigar, pipe, or mixed) was

\author{
Copenhagen \\ Center for \\ Prospective \\ Population Studies, \\ Danish \\ Epidemiology \\ Science Center at \\ the Institute of \\ Preventive \\ Medicine, \\ University of \\ Copenhagen, \\ Denmark \\ Eva Prescott, \\ senior research fellow \\ Merete Hippe, \\ research fellow \\ Jørgen Vestbo, \\ senior research fellow \\ Copenhagen City \\ Heart Study, \\ Bispebjerg Hospital, \\ University of \\ Copenhagen \\ Peter Schnohr, \\ senior consultant \\ Epidemiological \\ Research Unit, \\ Bispebjerg Hospital, \\ University of \\ Copenhagen \\ Hans Ole Hein, \\ associate professor \\ Correspondence to: \\ Dr Eva Prescott \\ Institute of \\ Preventive \\ Medicine, \\ Kommunehospitalet, \\ DK-1399 \\ Copenhagen K, \\ Denmark \\ eva.prescott@ \\ ipm.hosp.dk
}

BMJ 1998;316:1043-7

Table 1 Overview of study population

\begin{tabular}{lrrccc} 
Cohort of origin* & $\begin{array}{c}\text { No of } \\
\text { women }\end{array}$ & $\begin{array}{c}\text { No of } \\
\text { men }\end{array}$ & $\begin{array}{c}\text { Year of } \\
\text { examination }\end{array}$ & $\begin{array}{c}\text { Age at } \\
\text { examination }\end{array}$ & $\begin{array}{c}\text { No of } \\
\text { myocardial } \\
\text { infarctions }\end{array}$ \\
\hline Copenhagen city heart study & 8395 & 7033 & $1976 / 81$ & $20-93$ & 1368 \\
\hline Glostrup population studies & 547 & 503 & 1976 & 40 & 30 \\
\hline & 1828 & 1889 & 1982 & $30-60$ & 119 \\
\hline Copenhagen male study & 702 & 695 & 1987 & $30-60$ & 25 \\
\hline Total & - & 3071 & 1985 & $45-64$ & 221 \\
\hline
\end{tabular}

${ }^{*}$ Subjects with myocardial infarction before enrolment $(n=627)$, double participants $(n=191)$, and subjects lost to follow up $(n=1)$ were excluded. 
recorded for current smokers, as were years of smoking for both current and former smokers. Current tobacco consumption was calculated by equating a cigarette to $1 \mathrm{~g}$ tobacco, a cheroot to $3 \mathrm{~g}$ tobacco, and a cigar to $5 \mathrm{~g}$ tobacco. Pack years in current smokers was calculated as years of smoking multiplied by packs (of 20 cigarettes) currently consumed.

Arterial blood pressure was measured with the subject in a sedentary position after at least five minutes' rest. Blood lipids were non-fasting in the Copenhagen city heart study and fasting in the remaining cohorts. Body mass index was calculated as weight $(\mathrm{kg})$ divided by height squared $\left(\mathrm{m}^{2}\right)$. Educational level was divided into three categories: $<8$ years of schooling (completed primary school), 8-11 years, and $>11$ years. Alcohol consumption was classified according to total weekly intake: $<1$ drink per week, 1-6 drinks, 7-13 drinks, 14-27 drinks, 28-41 drinks, and $>41$ drinks; one drink contained 9-13 g alcohol. Physical activity in leisure time was classified into three categories as sedentary; moderate activity $<4$ hours per week; and moderate activity $>4$ hours per week. Self reported diabetes was defined as an affirmative answer to the question "Do you have diabetes?"

Subjects were followed until 31 December 1993 for fatal and non-fatal myocardial infarction (ICD-8 diagnosis code 410); the information was obtained from the National Board of Health or the National Hospital Discharge Register. Subjects with myocardial infarction before enrollment were excluded; analyses therefore concern first myocardial infarction only.

\section{Statistical analysis}

Arterial blood pressure, total and high density lipoprotein cholesterol concentrations, triglyceride concentrations, height, weight, and body mass index were divided into fifths within cohorts, by sex and by 10 year age groups. In this way differences in methods of measurement between the three cohorts were taken into account. Association between risk factors and myocardial infarction was analysed by using Cox proportional hazards regression models with age as underlying timescale and delayed entry accordingly. Relative risks for covariates other than smoking did not differ between men and women, and the final analyses were performed on the pooled data stratified by sex;

Table 2 Background characteristics and risk factors by sex. Values are mean (SD) unless otherwise indicated

\begin{tabular}{|c|c|c|c|}
\hline Characteristic & Women ( $n=11472)$ & Men $(n=13$ 191) & $P$ value \\
\hline Age (years) & $49.7(12.4)$ & $52.5(12.6)$ & $<0.001$ \\
\hline Body mass index $\left(\mathrm{kg} / \mathrm{m}^{2}\right)$ & $24.4(4.4)$ & $25.6(3.6)$ & $<0.001$ \\
\hline Systolic blood pressure ${ }^{*}(\mathrm{~mm} \mathrm{Hg})$ & $130.4(22.3)$ & $135.6(20.5)$ & $<0.001$ \\
\hline Diastolic blood pressure $^{*}(\mathrm{~mm} \mathrm{Hg})$ & $79.2(12.0)$ & $83.3(12.3)$ & $<0.001$ \\
\hline Plasma cholesterol* $(\mathrm{mmol} / \mathrm{l})$ & $6.16(1.28)$ & $5.98(1.19)$ & $<0.001$ \\
\hline Plasma triglyceride* $(\mathrm{mmol} / \mathrm{l})$ & $1.37(0.85)$ & $1.89(1.41)$ & $<0.001$ \\
\hline High density lipoprotein cholesterol ${ }^{\star}(\mathrm{mmol} / \mathrm{l})$ & $1.49(0.46)$ & $1.26(0.37)$ & $<0.001$ \\
\hline No $(\%)$ current smokers & $6461(56.3)$ & $8490(64.5)$ & $<0.001$ \\
\hline Daily tobacco consumptiont(g) & $13.8(7.9)$ & $17.9(9.8)$ & $<0.001$ \\
\hline No (\%) with <8 years education & $5071(44.2)$ & $6081(46.1)$ & 0.003 \\
\hline No (\%) physically inactive in leisure time & $2719(23.7)$ & $2454(18.6)$ & $<0.001$ \\
\hline No (\%) with intake $>14$ drinks/week & $987(8.6)$ & 5514 (41.8) & $<0.001$ \\
\hline No (\%) with self reported diabetes & 149 (1.3) & $303(2.3)$ & $<0.001$ \\
\hline
\end{tabular}

${ }^{*}$ In men, based on 10120 subjects. Subjects from Copenhagen male study excluded because of difference in method of measurement.

†Among current smokers.

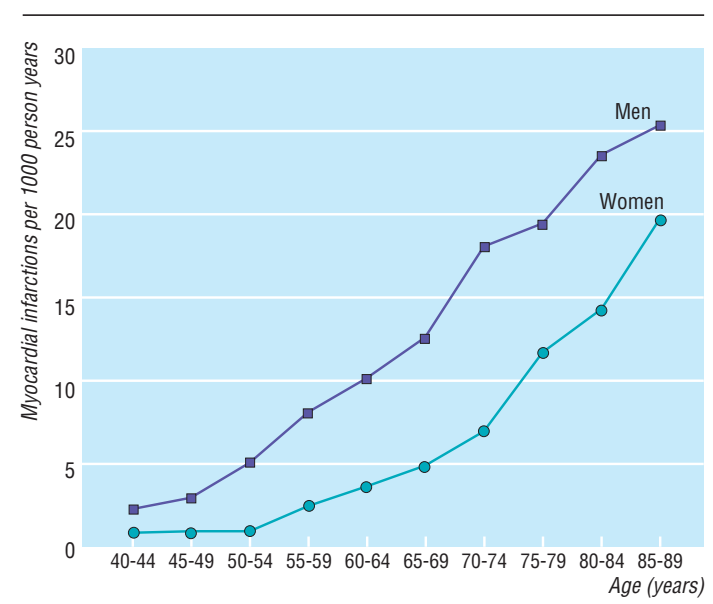

Fig 1 Age specific incidence rate of myocardial infarction in 11472 women and 13191 men from Copenhagen

this assumed the same effect of covariates in men and women but allowed for different baseline hazard in men and women. All covariates were treated as categorical variables as described above, and tests for interaction were done by using the likelihood ratio test. There were no significant interactions between sex and cardiovascular risk factors other than smoking. Both incidence rate and distribution of risk factors differed in the three study groups, but risk estimates did not differ. We therefore report results from the pooled data adjusted for cohort of origin. Incidence rates were based on number of events and person years of observation in 5 year age bands. The Stata statistical package was used for estimation. ${ }^{6}$

\section{Results}

Analyses were based on 11472 women and 13191 men (table 1). During follow up, 512 women and 1251 men had myocardial infarctions, of which 104 and 274, respectively, were fatal.

With the exception of alcohol consumption and physical activity, men had a more disadvantageous cardiovascular risk profile (table 2).

Figure 1 shows age and sex specific incidence rates of myocardial infarction. Men had higher incidence rates than women at all ages but the male-female risk ratio decreased from about 3 in the younger groups to 1.5 in older groups.

Systolic blood pressure, diastolic blood pressure, total and high density lipoprotein cholesterol concentrations, triglyceride concentrations, body mass index, height, education, alcohol intake, leisure time physical activity, and diabetes were all strongly associated with risk of myocardial infarction, and relative risks were similar in men and women.

Female current smokers had a relative risk of 2.24 (range 1.85-2.71) and male smokers 1.43 (1.26-1.62) relative to non-smokers. This difference was significant (ratio 1.57 (1.25-1.97), $\mathrm{P}=<0.001$ ) and was not changed after multiple adjustment for other risk factors. Risk in ex-smokers was not increased, but in current smokers there was a clear dose-response relation from a relative risk of $1.70(1.31-2.21)$ and 1.26 (0.98-1.61) in female and male non-inhalers, respec- 
Table 3 Relative risk (95\% confidence interval) of myocardial infarction by current tobacco exposure in 11472 women and 13191 men. Results from Cox proportional hazards regression analysis

\begin{tabular}{|c|c|c|c|c|c|c|}
\hline \multirow[b]{2}{*}{ Smoking status } & \multicolumn{3}{|c|}{ Unadjusted $^{*}$} & \multicolumn{3}{|c|}{ Adjusted† } \\
\hline & Women & Men & Ratio & Women & Men & Ratio \\
\hline Never smoker & 1.0 & 1.0 & 1.0 & 1.0 & 1.0 & 1.0 \\
\hline Ex-smoker & 0.99 (0.71 to 1.38) & $1.14(0.90$ to 1.44$)$ & 0.87 (0.58 to 1.30$)$ & 1.05 (0.74 to 1.50$)$ & 1.11 (0.86 to 1.42$)$ & 0.95 (0.61 to 1.46$)$ \\
\hline \multicolumn{7}{|l|}{ Current smoker: } \\
\hline Non-inhaling & 1.70 (1.31 to 2.21$)$ & $1.26(0.98$ to 1.61$)$ & 1.35 (0.94 to 1.94$)$ & 1.82 (1.39 to 2.41$)$ & 1.37 (1.06 to 1.78$)$ & 1.33 (0.91 to 1.94$)$ \\
\hline \multicolumn{7}{|l|}{ Inhaling: } \\
\hline $1-14 \mathrm{~g} /$ day & 2.59 (1.98 to 3.38$)$ & 1.52 (1.19 to 1.95$)$ & 1.70 (1.18 to 2.44$)$ & 2.76 (2.08 to 3.68$)$ & $1.60(1.24$ to 2.07$)$ & 1.72 (1.18 to 2.53 ) \\
\hline $15-24 \mathrm{~g} /$ day & 2.99 (2.25 to 3.99$)$ & 1.72 (1.37 to 2.17$)$ & 1.74 (1.20 to 2.51$)$ & 3.27 (2.42 to 4.42 ) & 1.75 (1.37 to 2.23$)$ & 1.87 (1.27 to 2.75 ) \\
\hline$>24 \mathrm{~g} /$ day & 3.31 (1.91 to 5.73 ) & 2.08 (1.60 to 2.69$)$ & 1.60 (0.87 to 2.93$)$ & 2.82 (1.45 to 5.46$)$ & 2.09 (1.58 to 2.77 ) & 1.34 (0.66 to 2.75$)$ \\
\hline Test for interaction $\ddagger$ & & & $P=0.002$ & & & $P=0.005$ \\
\hline
\end{tabular}

*Adjusted for age and cohort.

†Cox regression model stratified by sex and adjusted for age, cohort of origin, smoking status, sex, systolic blood pressure, diastolic blood pressure, cholesterol, triglyceride, body mass index, education, alcohol, diabetes, physical activity, and height.

fLikelihood ratio test for interaction between smoking and sex.

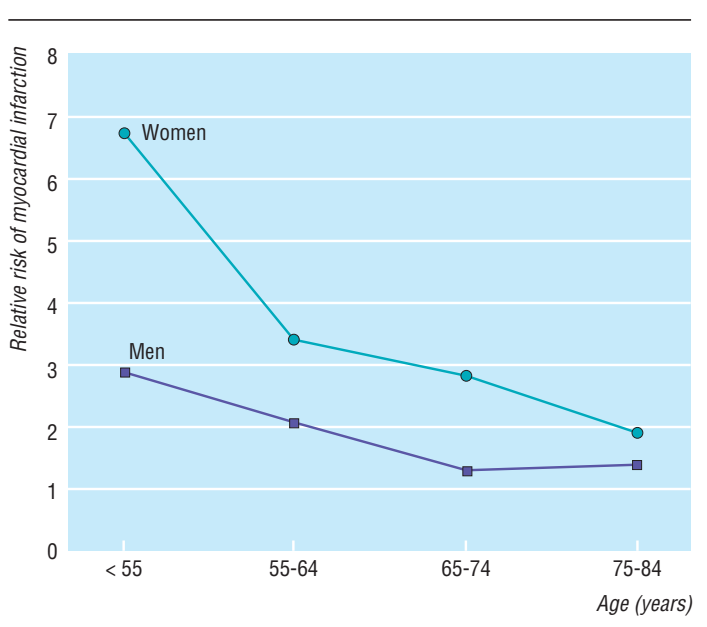

Fig 2 Relative risk of myocardial infarction for inhaling current smokers compared with never smokers

tively, to a maximum of $3.31(1.91-5.73)$ and $2.08(1.60-$ 2.69) in heavy smokers (table 3). All risk estimates were higher in women than in men and were not affected by adjustment for other major risk factors, as indicated. Similar results were seen after categorisation by pack years: maximum risk was seen in inhaling smokers of more than 30 pack years $(3.26(2.36-4.50)$ in women, 1.76 (1.41-2.19) in men; ratio 2.13 (1.48-3.07)). There was no interaction between smoking and other risk factors.

Figure 2 shows relative risk for inhaling current smokers versus never smokers by age in men and women up to age 85 . The risk of myocardial infarction decreased with age but was higher in women at all ages. The interaction term between smoking and sex did not differ in the four 10 year intervals $(P=0.73)$ and when the age dependence of the risk associated with smoking was adjusted for, the overall ratio between female and male relative risk was 2.01 (1.39 to 2.90).

\section{Discussion}

In this prospective study of almost 25000 subjects the main result was that relative risk of myocardial infarction in female smokers exceeded that of male smokers by more than $50 \%$. This difference was not affected by multiple adjustment for major cardiovascular risk factors.

\section{Myocardial infarction}

Our end point was defined as ICD- 8 code 410 , ascertained from the Hospital Discharge Register and from registration of cause of death with the National Board of Health, and included both fatal and non-fatal myocardial infarction. Some infarctions did not lead to hospital admission or may have been coded differently, for instance as codes 411 (other acute ischaemic heart disease), 427 (symptomatic heart disease), and 795 (sudden death). However, only differential misclassification (related to both sex and smoking status) will bias results, and there is no reason to suspect this.

Incidence rates of myocardial infarction in men were similar to those in other studies but the rates in women were higher. This is consistent with reports showing that mortality in middle aged Danish women is among the highest in western Europe and is at least partly caused by the high prevalence of smoking. Consistent with the observation that ex-smokers reduce their excess risk of myocardial infarction by as much as 50\% within the first year after quitting, ${ }^{1}$ we found that myocardial infarction was more strongly associated with current exposure than with accumulated exposure to tobacco. This is in agreement with findings that the short term effects of components in tobacco smoke-on the haemodynamic system, for example-are more important than the chronic exposure in development of coronary thrombosis.

\section{Comparison by sex}

In a previous study we showed that female smokers have about a $50 \%$ higher relative risk of dying from vascular disease. ${ }^{5}$ The present study confirmed this sex difference and found that the difference is not affected by adjustment for other cardiovascular risk factors.

Our analyses were based on baseline smoking status. If substantially more men than women gave up smoking during follow up, this could explain some of the observed difference. In 11094 subjects in the Copenhagen city heart study who were re-examined after 5 years, $12.8 \%$ of men and $11.6 \%$ of women who smoked at baseline had given up smoking. As quitting rates were similar, this is not likely to have affected results.

A few studies have addressed the issue of sex difference in effect of smoking on ischaemic heart disease. ${ }^{4-12}$ In a large prospective Norwegian study that included 11843 subjects, relative risk of myocardial infarction was 3.3 in female current smokers 
and 1.9 in male current smokers after adjustment for total and high density lipoprotein cholesterol concentrations, triglyceride concentrations, body mass index, and systolic blood pressure. ${ }^{9}$ This study also showed that relative risks associated with other risk factors were similar in both sexes. In the West of Scotland study, in which 4696 women and 5714 men were followed for death from ischaemic heart disease, relative risk was 1.9 in women and 1.6 in men after adjustment for major risk factors. ${ }^{10}$ In a Swedish study that included 10945 twins, relative risk was 1.6 in female smokers and 1.4 in male smokers. ${ }^{11}$ However, the Framingham study found no significant relation between smoking and ischaemic heart disease in women, ${ }^{4}$ and in a study of death from ischaemic heart disease by LaCroix et al, which included 7178 subjects aged over 65 , relative risks were 1.6 in female smokers and 2.0 in male smokers, with no adjustment for other risk factors. ${ }^{12}$ In these and in other important studies of coronary mortality ${ }^{2313-15}$ an apparent lack of difference between the sexes in risk associated with smoking may be due to the extensive differences in smoking habits between male and female smokers from older birth cohorts.

Our results are based on a multiplicative model, which is the most widely used model in cardiovascular epidemiology. That cardiovascular risk factors should act multiplicatively is biologically plausible, given what we know of the pathogenesis of myocardial infarction. If effects of cardiovascular risk factors are additive, relative risks will vary between men and women simply because risks vary at baseline. In this and other studies, however, relative risks did not vary for the other cardiovascular risk factors examined, ${ }^{9}$ and the sex difference in effect of tobacco thus cannot simply be put down to differing baseline rates. Although relative risks are higher in women, suggesting differences in mechanism of action of tobacco in men and women, smoking may well cause more cases of myocardial infarction among men. In our study population, the difference in risk was higher in men to age 65 and in women after age 65 .

A possible cause of the sex difference is an interaction of some hormonal factors with components of the inhaled smoke. There is growing epidemiological evidence that women who smoke are relatively deficient in oestrogen: they have an earlier menopause, decreased risk of cancer of the endometrium, greater likelihood of osteoporosis and of osteoporotic fractures, and reduced incidence of a number of "minor" disorders such as uterine fibroids. ${ }^{16}$ Possible biological mechanisms have been suggested. ${ }^{16-18}$ Oestrogen deficiency, on the other hand, is associated with cardiovascular disease: rates of ischaemic heart disease increase sharply in women after menopause; young women with bilateral oophorectomy have an increased risk of ischaemic heart disease; and accumulating epidemiological data show that women who use hormone replacement therapy after menopause have lower rates of ischaemic heart disease. ${ }^{190}$ This mechanism may be by lowering low density lipoprotein and fibrinogen, increasing high density lipoprotein cholesterol, ${ }^{21}{ }^{22}$ increasing blood flow, and reducing artherosclerosis. ${ }^{193}$ Thus it is possible that tobacco smoke, in addition to the (partly unknown) mechanisms by which it increases risk of ischaemic heart disease in both men and women, interacts with sex hormones and thus increases risk of ischaemic heart disease relatively more in female smokers than in men. In support of this, Criqui et al found that hormone replacement therapy was protective only in smokers, ${ }^{24}$ and in a study based on the Copenhagen city heart study Lindenstrøm et al found that hormone replacement therapy reduced the risk of stroke only in smokers, ${ }^{25}$ results which have yet to be confirmed in other studies. Because of insufficient information on hormone replacement therapy we could not examine this.

\section{Conclusion}

Female smokers have a higher relative risk of myocardial infarction than male smokers, even after adjustment for major cardiovascular risk factors. This raises the question of whether tobacco smoke may be more harmful to women with regard to ischaemic heart disease, possibly because of constituents of tobacco smoke exerting anti-oestrogenic effects. Results from large ongoing clinical trials of hormonal replacement therapy may be able to elucidate this.

The Copenhagen Center for Prospective Population Studies (T I A Sørensen, G Jensen, H O Hein, T Jørgensen, N Keiding, J Vestbo, M Grøenbak) consists of the Glostrup population studies (T Jørgensen, H Ibsen, K Borch-Johnsen, $\mathrm{P}$ Thorvaldsen, T Thomsen), the Copenhagen male study (H O Hein, F Gyntelberg, P Suadicani) and the Copenhagen city heart study (G Jensen, P Schnohr, M Appleyard, P Lange, B Nordestgaard, M Grønbæk).

Contributors: EP had the original idea for the present study, performed the data analyses, and is guarantor for the paper. $\mathrm{MH}$ and JV participated in data analyses and contributed to the paper. $\mathrm{HOH}$ and PS participated in data collection. The paper was written jointly by $\mathrm{EP}, \mathrm{MH}, \mathrm{JV}, \mathrm{HOH}$, and PS.

Funding: Grants from the Danish Ministry of Health, the Health Insurance Fund, the Danish Heart Foundation, and the Danish Medical Research Council (12-1661-1).

Conflict of interest: None.

1 Department af Health and Human Services. Epidemiology. In: National Heart, Lung, and Blood Institute. Report of the Task Force on Research in Epidemiology and Prevention of Cardiovascular Diseases. Rockville, MD: PubEpidemiology and Prevention of Cardiovascular Diseases. Rockville,

2 Doll R, Gray R, Hafner B, Peto R. Mortality in relation to smoking: 22 years' observations on female British doctors. BMJ 1980;280:967-71.

3 Doll R, Peto R, Wheatley K, Gray R, Sutherland I. Mortality in relation to smoking: 40 years' observations on male British doctors. BMJ 1994:309:901-11.

4 Seltzer CC. Framingham study data and "established wisdom" about cigarette smoking and coronary heart disease. J Clin Epidemiol $1988 \cdot 42 \cdot 743-50$.

5 Prescott E, Osler M, Andersen PK, Hein HO, Borch-Johnsen K, Lange P, et al. Mortality in women and men in relation to smoking: results from the Copenhagen center for prospective population studies. Int J Epidemiol (in press).

6 StataCorp. Stata statistical software: release 5.0. College Station, TX: Stata Corporation, 1997.

7 Peto R, Lopez AD, Boreham J, Thun M, Heath C Jr. Mortality from smoking in developed countries, 1950-2000: indirect estimates from national vital statistics. Oxford: Oxford University Press, 1994

8 Nyboe J, Jensen G, Appleyard M, Schnohr P. Smoking and the risk of first acute myocardial infarction. Am Heart J 1991;122:438-47.

9 Njolstad I, Arnesen E, Lund Larsen PG. Smoking, serum lipids, blood pressure, and sex differences in myocardial infarction. A 12-year follow-up of the Finnmark study. Circulation 1996;93:450-456.

10 Janghorbani M, Hedley AJ, Jones RB, Zhianpour M, Gilmour WH. Gender differential in all-cause and cardiovascular disease mortality. Int $J$ Epidemiol 1993;22:1056-63.

11 Floderus B, Cederlöf R, Friberg L. Smoking and mortality: a 21-year follow-up based on the Swedish twin registry. Int J Epidemiol 1988; $17: 332-40$

12 LaCroix AZ, Lang J, Scherr PA, Wallace RB, Cornoni-Huntley J, Berkman $\mathrm{L}$, et al. Smoking and mortality among older men and women in three communities. N Engl J Med 1991;324:1619-25.

13 Davis MA, Neuhaus JM, Moritz DJ, Lein D, Barchlay JD, Murphy SP. Health behaviors and survival among middle-aged and older men and women in the NHANES I epidemiologic follow-up study. Prev Med 1994;23:369-76.

14 Tverdal A, Thelle D, Stensvold I, Leren P, Bjartveit K. Mortality in relation to smoking history: 13 years' follow-up of 68,000 Norwegian men and women 35-49 years. J Clin Epidemiol 1993;46:475-87. 
15 Thun MJ, Day Lally CA, Calle EE, Flanders WD, Heath CW Jr. Excess mortality among cigarette smokers: changes in a 20-year interval [with comments]. Am J Public Health 1995;85:1223-30.

16 Baron JA, Vecchia CL, Levi F. The antiestrogenic effect of cigarette smoke in women. Am J Obstet Gynecol 1990;162:502-14.

17 Michnovicz IJ, Hershcopf RJ, Naganuma H, Bradlow HL, Fishman J. Increased 2-hydroxylation of estradiol as a possible mechanism for the anti-estrogenic effect of cigarette smoking. $N$ Engl $J$ Med anti-estrogenic

1986;315:1305-9.
18 Michnovicz JJ, Hershcopf RJ, Haley NJ, Bradlow HL, Fishman J. Cigarette smoking alters hepatic estrogen metabolism in men: implication for atherosclerosis. Metabolism 1989;38:537-41.

19 Grodstein F, Stampfer M. The epidemiology of coronary heart disease and estrogen replacement in postmenopausal women. Prog Cardiovasc Dis $1995 \cdot 38: 199-210$

20 Stampfer MJ, Colditz GA, Willett WC, Manson JE, Rosner B, Speizer FE, et al. Postmenopausal estrogen therapy and cardiovascular disease. Tenyear follow-up from the nurses' health study [with comments]. $N$ Engl Med 1991;325:756-62.
21 Miller VT, Muesing RA, LaRosa JC. Effects of conjugated equine estrogen with and without three different progestogens on lipoproteins, high-density lipoprotein subfractions, and apolipoprotein A-4. Obstet Gynecol 1991;77:235-40.

22 Writing Group for the PEPI Trial. Effects of estrogen or estrogen/ progestin regimens on heart disease risk factors in postmenopausal women. JAMA 1995;273:199-208

23 Williams JK, Adams MR, Klopfenstein HS. Estrogen modulates response of atherosclerotic coronary arteries. Circulation 1990;81:1680-7.

24 Criqui MH, Suarez L, Barrett Connor E, McPhillips J, Wingard DI, Garland C. Postmenopausal estrogen use and mortality. Results from a prospective study in a defined, homogeneous community. Am J Epidemiol 1988; $128: 606-14$

25 Lindenstrøm E, Boysen G, Nyboe J. Lifestyle factors and risk of cerebrovascular disease in women. Stroke 1993:24:1468-72.

(Accepted 5 December 1997)

\title{
Ecological study of reasons for sharp decline in mortality from ischaemic heart disease in Poland since 1991
}

\author{
Witold A Zatonski, Anthony J McMichael, John W Powles
}

\begin{abstract}
Objective: To investigate the reasons for the decline in deaths attributed to ischaemic heart disease in Poland since 1991 after two decades of rising rates. Design: Recent changes in mortality were measured as percentage deviations in 1994 from rates predicted by extrapolation of sex and age specific death rates for 1980-91 for diseases of the circulatory system and selected other categories. Available data on national and household food availability, alcohol consumption, cigarette smoking, socioeconomic indices, and medical services over time were reviewed.

Main outcome measures: Age specific and age standardised rates of death attributed to ischaemic heart disease and related causes.

Results: The change in trend in mortality attributed to diseases of the circulatory system was similar in men and women and most marked $(>20 \%)$ in early middle age. For ages 45 to 64 the decrease was greatest for deaths attributed to ischaemic heart disease and atherosclerosis (around 25\%) and less for stroke $(<10 \%)$. For most of the potentially explanatory variables considered, there were no corresponding changes in trend. However, between 1986-90 and 1994 there was a marked switch from animal fats (estimated availability down 23\%) to vegetable fats (up 48\%) and increased imports of fruit. Conclusion: Reporting biases are unlikely to have exaggerated the true fall in ischaemic heart disease; neither is it likely to be mainly due to changes in smoking, drinking, stress, or medical care. Changes in type of dietary fat and increased supplies of fresh fruit and vegetables seem to be the best candidates.
\end{abstract}

\section{Introduction}

From 1960 to 1991 mortality from diseases of the circulatory system in Poland was high and increasing. Death certification rates for this group of causes rose by about $70 \%$ in men and $15 \%$ in women, and in both sexes mortality from ischaemic heart disease roughly doubled. ${ }^{1-4}$ Since 1991, however, the fall in death certification rates for ischaemic heart disease seems to have been larger than that previously observed in any country in peacetime. This sharp change in trend suggests a curtailment of the final, fatal steps of the disease in people with advanced coronary atherosclerosis.

The unplanned natural experiments taking place in Poland and neighbouring countries in association with the unusually rapid political and economic transformations that began in the late 1980s may elucidate why mortality from ischaemic heart disease varies more between populations and over time than has previously been accounted for by the classic risk factors. ${ }^{5}$ Analyses in populations may yield such leads, notwithstanding the difficulties they face in taking adequate account of concurrent changes in confounders. ${ }^{6}$ Such analyses may point to widely shared influences on disease incidence, especially those acting late in the disease process. ${ }^{\text {? }}$

We considered the possible roles of concomitant changes in the availability of foods and alcohol, smoking prevalence, socioeconomic indices, and medical care in explaining the recent decline in mortality from ischaemic heart disease in Poland.

\section{Subjects and methods}

Mortality data are from the Polish system of vital statistics and the mortality data bank of the World Health Organisation in Geneva. There were no significant inconsistencies between the two data sets.

National death certification rates were examined for five year age groups between 35 and $\geqslant 85$ for 1970 94. Rates for ages 45-64 were standardised by five year age groups using weights of $6,5,4$, and 4 respectively. ${ }^{8}$ To minimise the effects of short term perturbations in rates around 1989-91, the subsequent changes in rates were measured as the percentage deviations in the reported rates for 1994 from rates predicted for 1994 by extrapolating the linear trends for 1980-91 (after
Department of Epidemiology and Cancer Prevention, Maria

Sklodowska-Curie Memorial Cancer Centre and Institute of Oncology, 02-781 Warsaw, Poland

Witold A Zatonski, professor

Department of Epidemiology and Population

Sciences, London School of Hygiene and Tropical

Medicine, London

WC1E 7HT

Anthony J

McMichael,

professor

Institute of Public Health, Cambridge CB2 2SR

John W Powles,

lecturer

Correspondence to: Professor Zatonski zatonskiw@ coi.waw.pl

BMJ 1998;316:1047-51 